\title{
Development and characterization of a novel rat model of estrogen- induced mammary cancer
}

\author{
Kirsten L Dennison', Nyssa Becker Samanas ${ }^{1}$, Quincy Eckert Harenda', \\ Maureen Peters Hickman', Nicole L Seiler ${ }^{1}$, Lina Ding ${ }^{1,2}$ and James D Shull, 2,3 \\ ${ }^{1}$ McArdle Laboratory for Cancer Research, Department of Oncology, School of Medicine and Public Health, \\ ${ }^{2}$ School of Medicine and Public Health, Molecular and Environmental Toxicology Center, and ${ }^{3}$ School of Medicine \\ and Public Health, University of Wisconsin Carbone Cancer Center, University of Wisconsin, \\ 1111 Highland Avenue, Madison, Wisconsin 53705, USA
}

\author{
Correspondence \\ should be addressed \\ to J D Shull \\ Email \\ shull@oncology.wisc.edu
}

\begin{abstract}
The $\mathrm{ACl}$ rat model of $17 \beta$-estradiol $\left(\mathrm{E}_{2}\right)$-induced mammary cancer is highly relevant for use in establishing the endocrine, genetic, and environmental bases of breast cancer etiology and identifying novel agents and strategies for preventing breast cancer. $E_{2}$ treatment rapidly induces mammary cancer in female $\mathrm{ACl}$ rats and simultaneously induces pituitary lactotroph hyperplasia and adenoma. The pituitary tumors can result in undesired morbidity, which compromises long-term studies focused on mammary cancer etiology and prevention. We have defined the genetic bases of susceptibility to $E_{2}$-induced mammary cancers and pituitary tumors and have utilized the knowledge gained in these studies to develop a novel inbred rat strain, designated ACWi, that retains the high degree of susceptibility to $E_{2}$-induced mammary cancer exhibited by $\mathrm{ACl}$ rats, but lacks the treatment-related morbidity associated with pituitary lactotroph hyperplasia/adenoma. When treated with $E_{2}$, female ACWi rats developed palpable mammary cancer at a median latency of 116 days, an incidence of $100 \%$ by 161 days and exhibited an average of 15.6 mammary tumors per rat following 196 days of treatment. These parameters did not differ from those observed for contemporaneously treated $\mathrm{ACl}$ rats. None of the $\mathrm{E}_{2}$-treated $\mathrm{ACWi}$ rats were killed before the intended experimental end point due to any treatment-related morbidity other than mammary cancer burden, whereas $20 \%$ of contemporaneously treated $\mathrm{ACI}$ rats exhibited treatment-related morbidity that necessitated premature killing. The ACWi rat strain is well suited for use by those in the research community, focusing on breast cancer etiology and prevention.
\end{abstract}

\author{
Key Words \\ - ACWi rat \\ - $\mathrm{ACl}$ rat \\ - Copenhagen rat \\ - estradiol \\ - breast cancer
}

\section{Introduction}

Both endogenous and exogenous estrogens have been strongly linked to the etiology of breast cancer (Yager \& Davidson 2006). Although it is clear that estrogen receptor (ER)-dependent pathways are essential for the development of a large fraction of breast cancers, the molecular mechanisms through which estrogens contribute to breast cancer etiology remain poorly defined. The ACI rat model of $17 \beta$-estradiol $\left(\mathrm{E}_{2}\right)$-induced mammary cancer serves as a unique and physiologically relevant model for defining the mechanisms through which estrogens contribute to

Published by Bioscientifica Ltd
Endocrine-Related Cancer (2015) 22, 239-248 
breast cancer development, identifying genetic variants that determine susceptibility to breast cancer, and identifying agents and strategies for use in preventing breast cancer. Female ACI rats rapidly develop mammary carcinoma when treated continuously with physiological levels of $\mathrm{E}_{2}$ normally encountered during pregnancy (Shull et al. 1997). Concurrent treatment with tamoxifen dramatically diminishes the ability of $\mathrm{E}_{2}$ to induce mammary cancer in ACI rats, indicating an important role of ER-mediated pathways in mammary tumorigenesis (Li et al. 2002, Singh et al. 2011). The mammary cancers that develop in $\mathrm{E}_{2}$-treated $\mathrm{ACI}$ rats express $\mathrm{ER} \alpha$ and progesterone receptor, are dependent upon estrogens for survival and growth, and exhibit non-random patterns of chromosome copy number alterations that mirror somatic copy number alterations frequently observed in breast cancers (Harvell et al. 2000, Adamovic et al. 2007, Ruhlen et al. 2009). Together, these data illustrate multiple important similarities between the mammary cancers induced by $\mathrm{E}_{2}$ in $\mathrm{ACI}$ rats and luminal type breast cancers in humans.

The ACI rat model of $\mathrm{E}_{2}$-induced mammary cancer has been extensively characterized genetically. Although female ACI rats are uniquely susceptible to mammary cancer induction by $\mathrm{E}_{2}$, female Copenhagen (COP) and Brown Norway (BN) rats are resistant (Shull et al. 1997, 2001, Spady et al. 1998, Shull 2007). Multiple quantitative trait loci (QTLs), designated estrogen-induced mammary cancer (Emca1) through Emca9, that harbor genetic determinants of susceptibility to $\mathrm{E}_{2}$-induced mammary cancer have been mapped in intercrosses between susceptible ACI rats and resistant COP or BN rats (Gould et al. 2004, Schaffer et al. 2006, Shull 2007). The existence of these Emca loci has been confirmed by generation and characterization of congenic rat strains that harbor alleles from the resistant COP or BN strain on the genetic background of the susceptible ACI strain (Schaffer et al. 2013, Colletti et al. 2014). Moreover, each of the Emca loci is orthologous to genetic determinants of breast cancer risk mapped in genome wide association studies (Schaffer et al. 2013, Colletti et al. 2014). These data strongly suggest that these rat models of $\mathrm{E}_{2}$-induced mammary cancer share multiple genetic determinants of breast cancer risk with humans.

Continuous treatment with naturally occurring or synthetic estrogens induces pituitary lactotroph hyperplasia and/or adenoma in multiple inbred rat strains (Stone et al. 1979, Wiklund et al. 1981a, Spady et al. 1999a). ACI rats are among the most highly sensitive of inbred strains in this regard, and morbidity resulting from these pituitary tumors can compromise long-term studies focused on mammary cancer etiology and prevention (Shull et al. 1997, Spady et al. 1999a). By contrast, COP rats are only moderately sensitive and $\mathrm{BN}$ rats are relatively insensitive to the actions of estrogens in the induction of lactotroph hyperplasia/adenoma (Wendell \& Gorski 1997, Spady et al. 1998, 1999a,c, Wendell et al. 2000, Strecker et al. 2005, Shull et al. 2007, Kurz et al. 2008, 2014). Multiple QTLs, designated estrogen-induced pituitary tumor (Ept1) through Ept14 have been mapped that determine the sensitivity to estrogen-induced lactotroph hyperplasia/ adenoma in intercrosses between $\mathrm{ACI}$ and $\mathrm{COP}$ or $\mathrm{BN}$ rats (Strecker et al. 2005, Shull et al. 2007, Kurz et al. 2008, 2014). The data from these studies indicate that most of the QTLs that determine responsiveness of the pituitary lactotroph to estrogens segregate independently from the QTLs that determine susceptibility to $\mathrm{E}_{2}$-induced mammary cancer. The objective of this study was to utilize the knowledge gained from genetic studies of estrogen action in the rat pituitary and mammary glands to develop a novel inbred rat strain that retains the high degree of susceptibility to $\mathrm{E}_{2}$-induced mammary cancer exhibited by ACI rats, but lacks the treatment-related morbidity associated with pituitary lactotroph hyperplasia/ adenoma. The data presented herein illustrate the unique phenotypic characteristics of such an inbred rat strain, designated ACWi. The ACWi rat strain is well suited for use by those in the community focusing on breast cancer etiology and prevention.

\section{Materials and methods}

\section{Care, treatment, and phenotypic characterization of animals}

All procedures involving live animals were approved by the Institutional Animal Care and Use Committee of the University of Wisconsin-Madison. ACI/SegHsd rats were obtained from Harlan Sprague-Dawley, Inc. (Indianapolis, IN, USA). COP/CrCrl rats were obtained from Charles River Laboratories (Wilmington, MA, USA). The ACI.COPEpt1 and ACI.COP-Ept2 congenic rat strains were generated in our laboratory as described previously (Kurz et al. 2008). The ACWi rat strain (official strain designation: ACI.COP-(D3Rat130-D3Rat114) (D6Rat80-D6Rat146)/ Shul, RGD ID 9589088) was generated by intercrossing the ACI.COP-Ept1 and ACI.COP-Ept2 strains and selectively breeding the progeny to generate animals that were homozygous for COP alleles at both the Ept1 locus on rat chromosome 6 (Rno6) and the Ept2 locus on Rno3.

Published by Bioscientifica Ltd 
The ACWi strain will be submitted to the Rat Resource and Research Center at the University of Missouri for cryopreservation and distribution. All rats were housed under controlled temperature, humidity, and $12 \mathrm{~h}$ light: $12 \mathrm{~h}$ darkness conditions in facilities that were accredited by the American Association for Accreditation of Laboratory Animal Care and operated in accordance with The Guide for the Care and Use of Laboratory Animals. All procedures related to the care, propagation, genotyping, treatment with $\mathrm{E}_{2}$, evaluation for presence of mammary cancer, and assessment of pituitary hyperplasia/ adenoma have been described (Shull et al. 1997, 2001, Spady et al. 1998, Harvell et al. 2000, Gould et al. 2004, Schaffer et al. 2006, 2013). The number of grossly discernible tumors, i.e., $\sim 1 \mathrm{~mm}$ in diameter, was quantified at necropsy. Pituitary mass was measured as a quantitative phenotypic indicator of pituitary lactotroph hyperplasia/adenoma as discussed below. The animals were killed following 84 days of treatment to evaluate pituitary mass or following $196(-4$ to +1$)$ days of treatment to evaluate mammary tumor burden together with pituitary mass. In the latter experiment, animals were killed before the desired experimental end point if necessary due to mammary tumor burden or another treatment-related morbidity.

\section{Sources of genomic data}

All genome coordinates presented in this manuscript are relative to rat genome assembly version 5.0. Wholegenome sequence data for $\mathrm{ACI}, \mathrm{COP}$, and $\mathrm{BN}$ rat strains were accessed through the Rat Genome Database and Ensembl Database (Laulederkind et al. 2013, Nigam et al. 2013, Flicek et al. 2014).

\section{Statistical analyses}

Latency was defined as the number of days separating initiation of $\mathrm{E}_{2}$ treatment and the first detection of a palpable mammary tumor. Phenotypes exhibited by ACWi rats were compared with those exhibited by contemporaneously treated ACI rats as well as to recent historical data from identically treated ACI and COP rats. Median latency was derived from Kaplan-Meier analyses. The log rank test was used to compare latencies between strains and to calculate the relative risk of each set of congenic rats in comparison with ACI rats. These analyses were carried out in MSTAT version 5.5 (Drinkwater 2013). Between-strain differences in mammary tumor multiplicity and pituitary mass at necropsy were evaluated using the Kruskal-Wallis and Wilcoxon rank sum tests with the Holm-Bonferroni method to correct for multiple pairwise comparisons. These analyses were carried out in $\mathrm{R}$ (R Core Team 2013). $P$ values $\leq 0.05$ were considered to be statistically significant for all tests.

\section{Results}

\section{ACWi rats are highly susceptible to $E_{2}$-induced mammary cancer}

The susceptibility of ACWi rats to $\mathrm{E}_{2}$-induced mammary cancer was compared with that of contemporaneously treated ACI rats to determine whether or not ACWi rats retained the highly susceptible phenotype that is the characteristic of the parental ACI rat strain. The median latency to the appearance of palpable mammary cancer for $\mathrm{E}_{2}$-treated ACWi rats was 116 days and $100 \%$ of the treated rats developed mammary cancer by 161 days of treatment (Fig. 1). Median latency for contemporaneously treated ACI rats was 100 days and $100 \%$ of the treated rats exhibited palpable mammary cancers by 134 days of treatment. The time course to the appearance of palpable mammary cancer in ACWi rats did not differ significantly from that in ACI rats $(P=0.071)$. Because the mammary

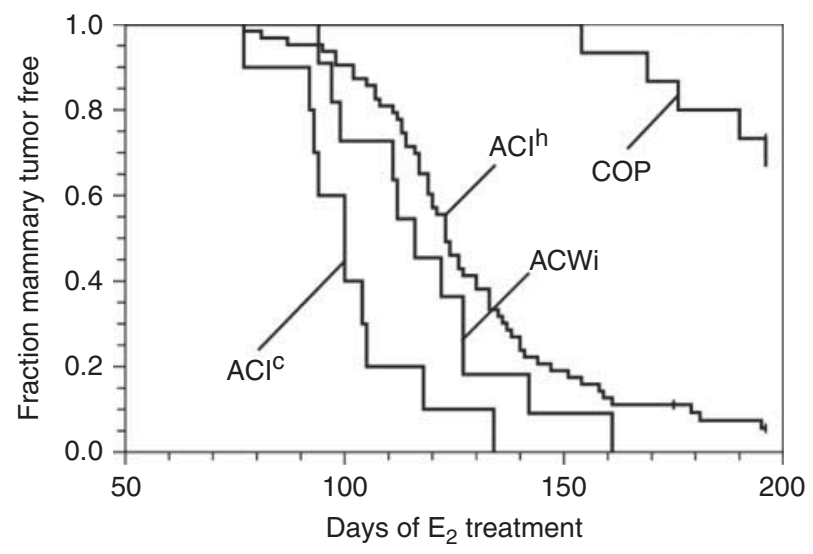

Figure 1

$A C W i$ and $A C l$ rats are highly susceptible to $E_{2}$-induced mammary cancer; an examination of latency to appearance and incidence of mammary cancer. Female ACWi $(n=11), \mathrm{ACl}\left(n=10\right.$ contemporaneous, $\mathrm{ACl}^{\mathrm{c}} ; n=63$ historical, $\left.\mathrm{ACl}^{\mathrm{h}}\right)$, and $\operatorname{COP}(n=15)$ rats were treated with $\mathrm{E}_{2}$, released continuously from s.c. silastic tubing implants, beginning at 9 weeks of age as described in Materials and methods. Thereafter, each rat was palpated once or twice weekly to detect mammary cancer. The data were subjected to Kaplan-Meier analyses. Each plot illustrates the number of days separating initiation of $E_{2}$ treatment and appearance of palpable mammary cancer or grossly apparent mammary cancer at necropsy. Sham-treated control ACWi, ACl, and COP rats did not develop mammary cancer over the illustrated time course.

Published by Bioscientifica Ltd. 


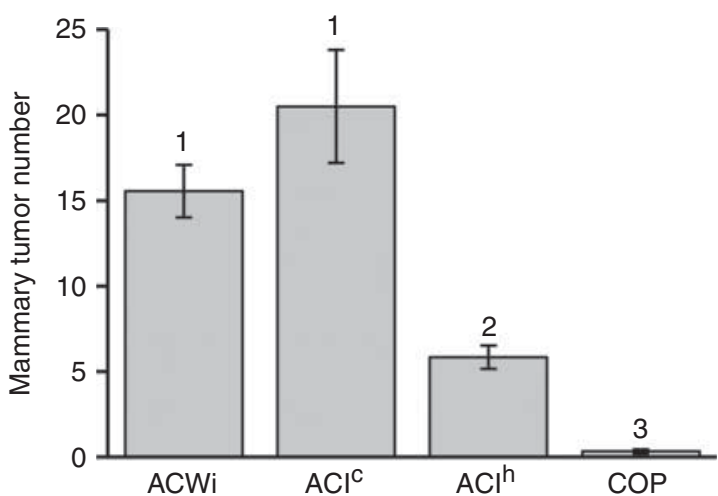

Figure 2

$\mathrm{ACWi}$ and $\mathrm{ACl}$ rats are highly susceptible to $\mathrm{E}_{2}$-induced mammary cancer; an examination of tumor multiplicity. Female ACWi, $\mathrm{ACl}$ (contemporaneous, $\mathrm{ACl}^{\text {c; }}$ historical, $\mathrm{ACl}^{\mathrm{h}}$ ), and COP rats were treated with $\mathrm{E}_{2}$ as described in Fig. 1 and Materials and methods. Each data bar indicates the mean number of mammary tumors ( \pm s.E.M.) observed at necropsy for rats treated for at least 160 days; $n=8-57$ animals per group. Data were evaluated using the Kruskal-Wallis and Wilcoxon rank sum tests with the Holm-Bonferroni method. Different numerals above the data bars indicate statistical significance $(P<0.05)$.

cancer phenotypes exhibited by ACI rats and different ACI-derived congenic rats have been observed to be stable over time and between laboratories, the susceptibility of ACWi rats to $E_{2}$-induced mammary cancer was also compared with historical data from identically treated ACI and COP rats evaluated in our laboratory. Median latency to the appearance of palpable mammary cancer in this larger group of $\mathrm{E}_{2}$-treated $\mathrm{ACI}$ rats was 123 days and $94 \%$ of the animals at risk developed mammary cancer by 196 days of treatment. As expected, COP rats were resistant to induction of mammary cancer by $E_{2}$, relative to ACI and ACWi rats. The first palpable cancer in this group of $\mathrm{E}_{2}$-treated $\mathrm{COP}$ rats was observed following 154 days of treatment and only 33\% of the treated COP rats developed mammary cancer during the course of treatment. The time course to the appearance of mammary cancer in $\mathrm{E}_{2}$-treated $\mathrm{ACW}$ i rats did not differ significantly from that exhibited by the group of ACI rats evaluated previously $(P=0.184)$, but did differ significantly from that exhibited by the $\mathrm{E}_{2}$-treated $\mathrm{COP}$ rats $(P<0.0001)$. Sham-treated control ACWi, ACI, and COP rats did not develop mammary cancer when evaluated over a 196-day time course.

Grossly discernable mammary tumors were enumerated at necropsy. The mean numbers of mammary tumors observed in contemporaneously treated ACWi and ACI rats were 15.6 and 20.5 , respectively, and mammary tumor number did not differ between strains ( $P=0.2822$; Fig. 2$)$.
Average mammary tumor number in the group of $\mathrm{E}_{2}$-treated ACI rats evaluated before the current study was 5.8 per rat, whereas average mammary tumor number in $\mathrm{E}_{2}$-treated COP rats was 0.3 per rat. Tumor number in ACWi rats differed significantly from that observed in these groups of ACI $(P<0.0001)$ and COP rats $(P<0.0001)$. Together, the data presented in Figs 1 and 2 clearly indicate that ACWi rats are as highly susceptible to $\mathrm{E}_{2}$-induced mammary cancer as ACI rats. The magnitude of the difference in average mammary tumor number observed between the contemporaneous and historical groups of ACI rats exceeded that normally observed between individual batches of ACI rats evaluated in our laboratory over the past several years. The bases for this observed difference between the contemporaneous and historical data are not known.

\section{ACWi rats do not exhibit morbidity resulting from $\mathrm{E}_{2}$-induced pituitary lactotroph hyperplasia/adenoma}

Continuous treatment of ACI rats with $\mathrm{E}_{2}$ or the synthetic estrogen diethylstilbestrol (DES) induces development of pituitary lactotroph hyperplasia/adenoma, and the resulting dramatic increase in pituitary gland mass and endocrine dysfunction (i.e., hyperprolactinemia) can result in morbidity that necessitates killing of an experimental animal before the intended experimental end point (Spady et al. 1999a). Therefore, we evaluated the impact on the survival of treatment-related morbidity that

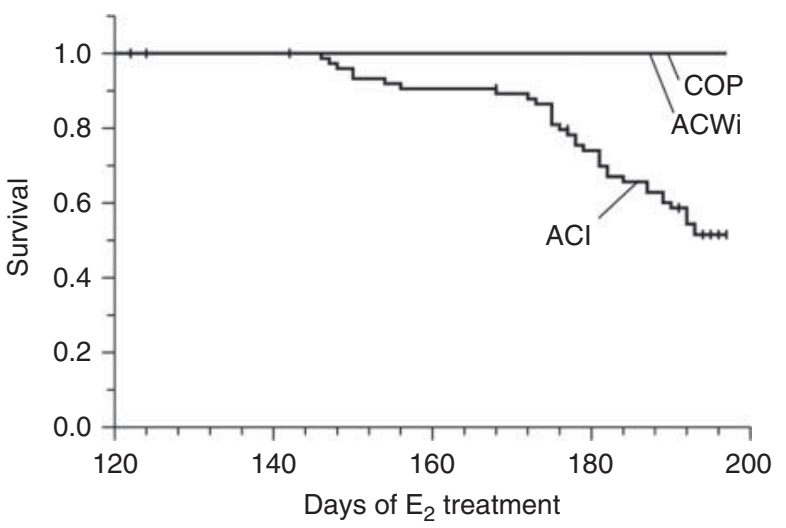

Figure 3

ACWi rats exhibit reduced treatment-related morbidity relative to $\mathrm{ACl}$ rats. Female $\mathrm{ACWi}, \mathrm{ACl}$, and COP rats were treated with $\mathrm{E}_{2}$ as described in Fig. 1 and Materials and methods. The impact of any treatment-related morbidity other than mammary tumor burden on survival was evaluated as a function of duration of $E_{2}$ treatment and the data were subjected to Kaplan-Meier analyses. Each plot illustrates the number of days separating initiation of $\mathrm{E}_{2}$ treatment and killing due to undesired treatment-related morbidity.

Published by Bioscientifica Ltd. 


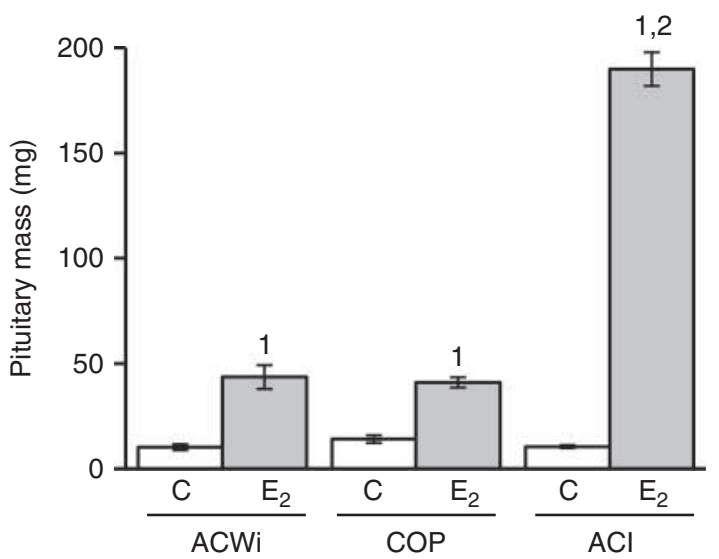

Figure 4

ACWi rats exhibit diminished pituitary growth response to estrogen relative to $\mathrm{ACl}$ rats. $\mathrm{ACWi}, \mathrm{COP}$, and $\mathrm{ACl}$ rats were treated as described in Fig. 1 and Materials and methods. Sham-treated control rats (C) received empty implants. $E_{2}$-treated animals received implants that release $E_{2}$ continuously. Pituitary mass, a surrogate indicator of absolute lactotroph number, was evaluated at necropsy. Average durations of $E_{2}$ treatment in the ACWi, COP, and ACl populations were 192, 196, and 185 days respectively. Each data bar indicates mean pituitary mass ( \pm s.E.M.). Data were evaluated using the Kruskal-Wallis and Wilcoxon rank sum tests with the Holm-Bonferroni method. Numerals above bars indicate statistical significance $(P<0.05): 1)$ within strain, relative to sham-treated controls and 2) with the same treatment, relative to ACWi.

resulted from any condition other than mammary cancer burden. No $\mathrm{E}_{2}$-treated ACWi or COP rats were killed due to any morbidity other than mammary cancer burden (Fig. 3). By contrast, $20 \%$ of the contemporaneously treated $\mathrm{ACI}$ rats and $49 \%$ of the $\mathrm{E}_{2}$-treated $\mathrm{ACI}$ rats evaluated in our laboratory over the past 4 years were killed due to morbidity other than mammary cancer burden before the intended experimental end point. The survival curves for the two groups of $\mathrm{E}_{2}$-treated $\mathrm{ACI}$ rats did not differ significantly $(P=0.3453)$, and these groups were combined for comparison with treated ACWi and COP rats (Fig. 3). Overall survival of $\mathrm{E}_{2}$-treated ACWi and $\mathrm{COP}$ rats was significantly higher relative to that observed in the combined population of $\mathrm{E}_{2}$-treated $\mathrm{ACI}$ rats $(P=0.0117$ and $P=0.0019$ respectively).

Pituitary gland mass was measured in all rats at necropsy. Pituitary mass in sham treated control ACWi, COP, and ACI rats averaged 10.2, 14.0, and $10.5 \mathrm{mg}$, respectively, and no significant differences were observed between strains (Fig. 4). $E_{2}$ treatment increased pituitary mass 4.3-fold in ACWi rats, from an average of $10.2 \mathrm{mg}$ in sham-treated control ACWi rats to an average of $43.5 \mathrm{mg}$ in $\mathrm{E}_{2}$-treated ACWi rats $(P=0.0420)$. Pituitary mass was similarly increased 2.9-fold in $\mathrm{E}_{2}$-treated COP rats, relative to sham-treated control COP rats $(P=0.0013)$.
By contrast, $\mathrm{E}_{2}$ treatment increased pituitary mass 15.5 fold $(P=0.0006)$ in contemporaneously treated ACI rats and 18.5-fold $(P<0.0001)$ in the historical ACI population. Because pituitary mass did not differ significantly between these two groups of $\mathrm{E}_{2}$-treated ACI rats, they were combined to simplify between strain comparisons. Pituitary mass in $\mathrm{E}_{2}$-treated ACWi and COP rats differed significantly from that observed in $\mathrm{E}_{2}$-treated $\mathrm{ACI}$ rats $(P<0.0001$ for both comparisons), whereas pituitary mass in treated ACWi and COP rats did not differ $(P=1)$. As noted above, a significant fraction of $\mathrm{E}_{2}$-treated $\mathrm{ACI}$ rats exhibited treatment-related morbidity and were killed before the desired experimental end point; i.e., 196 days of treatment. Average durations of $\mathrm{E}_{2}$ treatment in the ACWi, COP, and ACI populations were 192, 196, and 185 days respectively.

Ept1 and Ept2 were originally mapped in male F2 progeny that were generated in crosses between ACI and COP and treated with DES for 12 weeks, and the actions of these QTLs were subsequently confirmed in female congenic rats treated with $\mathrm{E}_{2}$ for 12 weeks (Strecker et al. 2005, Kurz et al. 2008). Therefore, we also evaluated pituitary mass in female ACWi and ACI rats that were treated with $\mathrm{E}_{2}$ for 12 weeks (Fig. 5). Treatment of ACWi rats with $\mathrm{E}_{2}$ for 12 weeks increased pituitary mass by 3.3-fold, from 10.3 to $34.2 \mathrm{mg}(P=0.0710)$. By contrast,

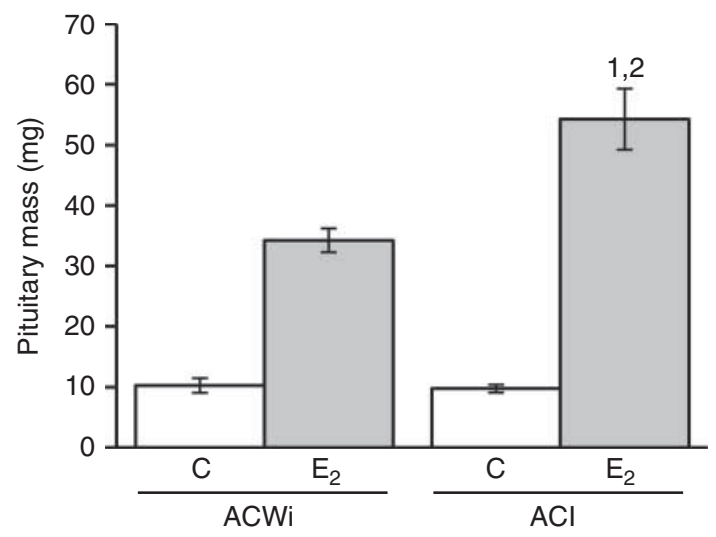

Figure 5

ACWi rats exhibit diminished pituitary growth response to estrogen relative to $\mathrm{ACl}$ rats; an examination following 12 weeks of treatment. $\mathrm{ACWi}$ and $\mathrm{ACl}$ rats were treated as described in Fig. 1 and Materials and methods. Sham-treated control rats (C) received empty implants. $E_{2}$-treated animals received implants that release $\mathrm{E}_{2}$ continuously. Pituitary mass was evaluated following 12 weeks of treatment. Each data bar indicates mean pituitary mass ( \pm s.E.M.). Data were evaluated using the Kruskal-Wallis and Wilcoxon rank sum tests with the Holm-Bonferroni method. Numerals above bars indicate statistical significance $(P<0.05): 1)$ within strain, relative to sham-treated controls and 2 ) with the same treatment, relative to $\mathrm{ACWi}$.

Published by Bioscientifica Ltd. 

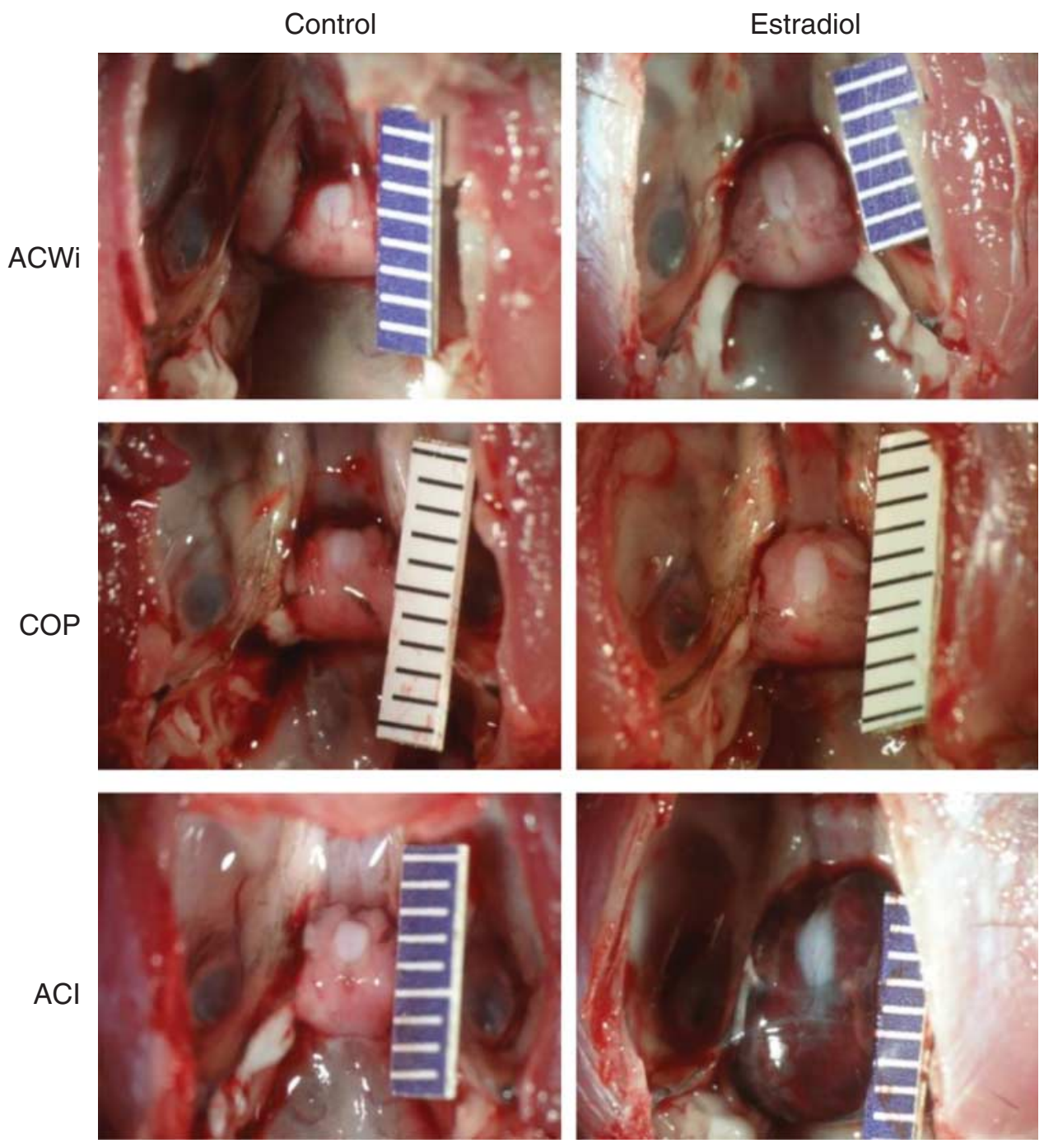

\section{Figure 6}

Effects of estrogen on pituitary gland morphology. Female $\mathrm{ACWi}, \mathrm{COP}$ and $\mathrm{ACl}$ rats were treated with $\mathrm{E}_{2}$ as described in Fig. 1 and Materials and methods. Each image illustrates the appearance of the pituitary gland from a representative ACWi, COP, or ACl rat that was either sham treated (control) or treated with estradiol $\left(E_{2}\right)$ for 195-196 days. Each graduation on the scale ruler indicates $1 \mathrm{~mm}$.

12 weeks of $\mathrm{E}_{2}$ treatment increased pituitary mass by 5.5fold in ACI rats $(P=0.0130)$. Average pituitary mass in treated ACWi rats was significantly less than in ACI rats following 12 weeks of treatment $(P=0.0350)$, further indicating that ACWi rats are less sensitive than ACI rats in regard to the induction of pituitary lactotroph hyperplasia/adenoma by $\mathrm{E}_{2}$.

The gross appearance of the pituitary glands of $\mathrm{E}_{2}$ treated rats also differed upon comparison by rat strain. The glands of $\mathrm{E}_{2}$-treated $\mathrm{ACWi}$ and COP rats were enlarged, but were normal in shape and color (Fig. 6). In addition, the posterior lobe of the pituitary gland remained apparent in $\mathrm{E}_{2}$-treated $\mathrm{ACWi}$ and $\mathrm{COP}$ rats.
The pituitary glands of $\mathrm{E}_{2}$-treated ACI rats were enlarged and were usually abnormal in shape and red in color, which results from the presence of abundant dilated and congested vascular channels and focal regions of hemorrhage (Spady et al. 1999a,b).

\section{Discussion}

Published genetic data from reciprocal intercrosses between ACI and COP rats indicate that the QTLs that determine susceptibility to $\mathrm{E}_{2}$-induced mammary cancer segregate independently of those QTLs that determine the sensitivity of the pituitary lactotroph population to

Published by Bioscientifica Ltd 
estrogen-induced hyperplasia/adenoma (Gould et al. 2004, Strecker et al. 2005). Using this knowledge, we developed the ACWi rat strain as a novel rat mammary cancer model that retains the unique susceptibility of the ACI rat to $\mathrm{E}_{2}$-induced mammary cancer while virtually eliminating treatment-related morbidity resulting from pituitary lactotroph hyperplasia/adenoma. The ACWi rat strain was generated by intercrossing previously described ACI.COP-Ept1 and ACI.COP-Ept2 congenic rats and selectively breeding to homozygosity for COP alleles at Ept1 on Rno6 and Ept2 on Rno3 (Kurz et al. 2008). This strategy was chosen because: i) for those QTLs where COP alleles reduced the sensitivity of the pituitary lactotroph to estrogen, Ept1 and Ept2 exerted the greatest effects on phenotypic variance and ii) pituitary lactotroph responsiveness in ACI.COP-Ept1 and ACI.COP-Ept2 congenic rats differed most from that of ACI rats (Strecker et al. 2005, Kurz et al. 2008). The responsiveness of the pituitary lactotroph population to $\mathrm{E}_{2}$ in ACWi rats, as indicated by quantification of pituitary mass, a surrogate indicator of absolute lactotroph number (discussed below), was dramatically reduced relative to $\mathrm{ACI}$ rats, and did not differ from that of COP rats. Comparison of the data from the current study with published data indicates that the combined actions of COP alleles at Ept1 and Ept2 on induction of pituitary lactotroph hyperplasia/adenoma in ACWi rats dramatically exceed the actions of COP alleles at either Ept1 or Ept2 alone (Kurz et al. 2008). Whereas pituitary mass in ACWi rats treated with $\mathrm{E}_{2}$ for 28 weeks averaged $43.4 \mathrm{mg}$, pituitary mass in identically treated
ACI.COP-Ept1 and ACI.COP-Ept2 rats averaged $142.7 \mathrm{mg}$ $(P<0.0001$ vs $\mathrm{ACWi})$ and $75.9 \mathrm{mg}(P=0.0033$ vs ACWi $)$ respectively.

The sensitivity of the pituitary lactotroph population to the induction of hyperplasia/adenoma by estrogen is rat strain-specific and highly heritable (Stone et al. 1979, Wiklund et al. 1981a,b, Wendell et al. 1996, Shull et al. 1997, 2007, Wendell \& Gorski 1997, Spady et al. 1999a,c, Strecker et al. 2005). Pituitary mass is frequently used as a quantitative phenotype for estrogen-induced lactotroph hyperplasia/adenoma (Wiklund et al. 1981a,b, Wendell et al. 1996, Wendell \& Gorski 1997, Spady et al. 1999a,c, Strecker et al. 2005, Shull et al. 2007). Because pituitary mass is directly correlated with pituitary DNA content and the level of prolactin in the systemic circulation, this phenotype serves as an accurate surrogate indicator of absolute lactotroph number (Wiklund et al. 1981a, Spady et al. 1999a,c, Tachibana et al. 2006, Kurz et al. 2008). Estrogen-induced lactotroph hyperplasia/adenoma results in sustained hyperprolactinemia (Spady et al. 1999a). Prolactin plays important roles in mammary gland development and lactation, and has been implicated in the etiology of breast cancer (Clevenger et al. 2003, Rose-Hellekant et al. 2003). ACWi rats remain as highly susceptible as parental $\mathrm{ACI}$ rats to $\mathrm{E}_{2}$-induced mammary cancer while the sensitivity of the pituitary lactotroph population in ACWi rats to induction of hyperplasia/ adenoma is significantly attenuated relative to ACI rats. These data further confirm that the molecular events that give rise to these two different estrogen-induced

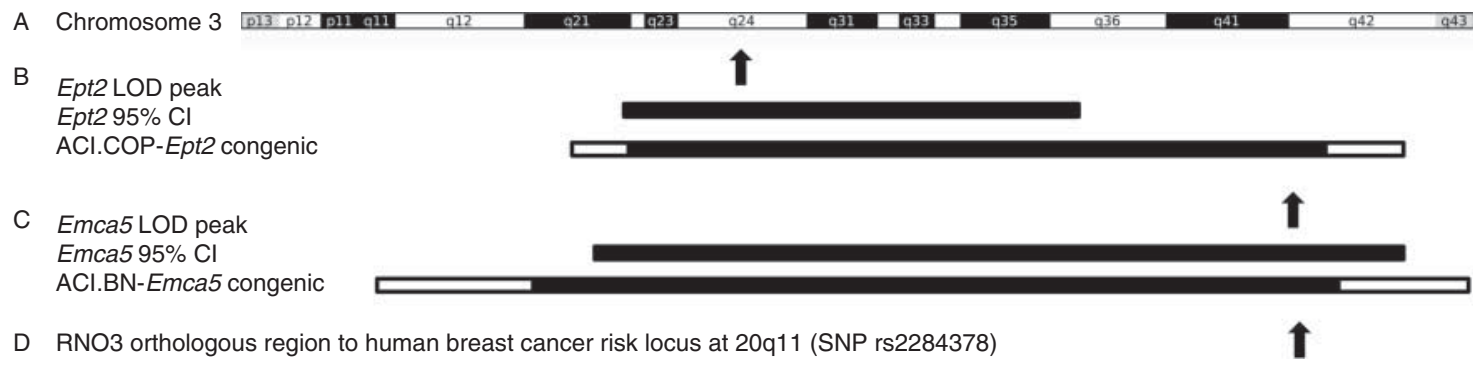

\section{Figure 7}

Genetic relationships between the Ept2 pituitary tumor locus and the Emca5 mammary cancer locus. (A) Rat chromosome 3 (RNO3) is illustrated as an ideogram that denotes defined cytogenetic bands. (B) Ept2 was mapped to $\mathrm{RNO} 3$ in intercrosses between $\mathrm{ACl}$ and COP rats (Strecker et al. 2005). The location of the Ept2 LOD peak is illustrated by the upward arrow above a horizontal black bar that indicates the $95 \% \mathrm{Cl}$ for Ept2, which was defined by interval mapping analyses. Also illustrated is the Ept2 congenic interval; the horizontal black bar indicates the segment of RNO3 that is known to be derived from COP rats, the open termini of this horizontal bar indicate areas of recombination between the $\mathrm{ACl}$ and $\mathrm{COP}$ genomes, and the remainder of $\mathrm{RNO} 3$ is known to be derived from $\mathrm{ACl}$ rats (Kurz et al. 2008). (C) Emca5 was mapped to RNO3 in an intercross between $\mathrm{BN}$ and $\mathrm{ACl}$ rats (Schaffer et al. 2006). The locations of the Emca5 LOD peak, the Emca5 $95 \% \mathrm{Cl}$, and the Emca5 congenic interval (Colletti et al. 2014) are illustrated as described for Ept2. (D) The upward arrow indicates the location of the region of RNO3 that is orthologous to the breast cancer risk locus in humans linked to single-nucleotide polymorphism rs2284378 in a genome wide association study (Siddiq et al. 2012). The overlap between the rat and human loci suggest these species share genetic determinants of breast cancer susceptibility (Colletti et al. 2014).

Published by Bioscientifica Ltd. 
neoplasms are influenced by distinct genetic determinants. Moreover, these data further illustrate the lack of a direct association between pituitary tumor mass, hyperprolactinemia, and susceptibility to $\mathrm{E}_{2}$-induced mammary cancer in the rat models.

The morbidity associated with pituitary lactotroph hyperplasia/adenoma in humans and estrogen-sensitive rat strains, such as ACI, results in large part from the effect of expanded pituitary mass on those tissues adjacent to the pituitary gland, primarily the hypothalamus and the optic nerves, as well as from endocrine imbalances, specifically hyperprolactinemia and/or deficiency of the other hormones normally produced by other pituitary cell types (Spady et al. 1999a, Molitch 2002, Sam \& Molitch 2005, Colao \& Savastano 2011). In this study, $46 \%$ of ACI rats treated with $\mathrm{E}_{2}$ to induce mammary cancer exhibited treatment-related morbidity unrelated to mammary cancer burden and were killed before the desired experiment end point. By contrast, $0 \%$ of $\mathrm{E}_{2}$-treated ACWi rats were killed before the completion of the study due to morbidity other than mammary cancer burden. In an effort to reduce treatment-related morbidity in $\mathrm{E}_{2}$-treated ACI rats, Ravoori et al. explored the use of a lower dose of $\mathrm{E}_{2}$ to induce mammary cancer, relative to that used in our studies. Although the lower $\mathrm{E}_{2}$ dose, achieved by reducing the length of the silastic tubing implant, was effective in reducing treatment-related morbidity, an extra 60 days of treatment was required to attain an equivalent mammary tumor multiplicity observed in ACI rats treated with the larger implants/higher dose of $\mathrm{E}_{2}$ (Ravoori et al. 2007). Thus, ACWi rats offer clear advantages over ACI rats to those investigators who perform long-term studies focused on the etiology and prevention of $\mathrm{E}_{2}$-induced mammary cancer using these physiologically relevant rat models.

The ACWi rat strain was developed by intercrossing ACI.COP-Ept1 and ACI.COP-Ept2 rats followed by iterative inbreeding with selection for COP alleles at Ept1 and Ept2. It is noteworthy that the Ept2 congenic interval on RNO3 extends from D3Mgh21 (48.4 Mb) to D3Rat142 $(171.5 \mathrm{Mb})$ and overlaps almost entirely with Emca5, a mammary cancer susceptibility QTL that was mapped in an intercross between susceptible ACI and resistant $\mathrm{BN}$ rats (Fig. 7; Strecker et al. 2005, Schaffer et al. 2006, Kurz et al. 2008, Colletti et al. 2014). Data presented herein as well as data published previously indicate that COP alleles across the Ept2 congenic interval do not impact susceptibility to $\mathrm{E}_{2}$-induced mammary cancer, whereas $\mathrm{BN}$ alleles across the Emca5 congenic interval dramatically reduce mammary cancer susceptibility (Kurz et al. 2008, Colletti et al.
2014). Together, these data suggest that the genetically related ACI and COP rat strains share alleles at Emca5. The peak LOD region of Emca5 is orthologous to a breast cancer risk locus mapped to human chromosome 20q11 that spans three genes, ASIP, RALY, and EIF2S2 (Schaffer et al. 2006, Siddiq et al. 2012, Colletti et al. 2014). ASIP encodes agouti signaling protein, which regulates skin and hair pigmentation in humans and multiple other mammalian species, including rats (Kanetsky et al. 2002, Bonilla et al. 2005, Suzuki 2013). It is interesting to note that BN alleles at Emca5 confer upon ACI.BN-Emca5 congenic rats a black, non-agouti, coat color phenotype, indicating that ACI and BN rats harbor different alleles at Asip (J D Shull, unpublished observations). By contrast, both ACI and ACI.COP-Ept2 congenic rats exhibit the agouti coat color, indicating that ACI and COP strains share alleles at Asip. An evaluation of available whole-genome sequence data for the ACI, COP, and BN rat strains further supports the assertion that $\mathrm{ACI}$ and $\mathrm{COP}$ rats share alleles across the peak LOD region of Emca5, including the Asip locus, whereas $\mathrm{BN}$ rats differ across this region. Together, these comparative genomic data indicate that $\mathrm{BN}$ rats harbor a genetic variant that inhibits production or function of agouti signaling protein and suggest a possible functional association between this genetic variant and mammary cancer susceptibility.

\section{Declaration of interest}

The authors declare that there is no conflict of interest that could be perceived as prejudicing the impartiality of the research reported.

\section{Funding}

This work was supported by grant R01-CA77876 from the National Institutes of Health (NIH). Shared research resources at the University of Wisconsin-Madison were supported by Cancer Center Support Grant P30-CA014520.

\section{Author contribution statement}

$\mathrm{K}$ L Dennison and N B Samanas generated the ACWi rat strain. K L Dennison, N B Samanas, Q E Harenda, M P Hickman, N L Seiler, and L Ding generated data. K L Dennison and J D Shull evaluated data and prepared the manuscript. J D Shull conceived and directed the study and was the primary author of the manuscript.

\section{Acknowledgements}

The authors thank John Colletti for his contribution to this research. We also thank the staff of the Experimental Pathology Shared Service in the UW Carbone Cancer Center and staff of the Animal Care Core in the McArdle Laboratory for Cancer Research for their valuable contributions to this research.

Published by Bioscientifica Ltd. 


\section{References}

Adamovic T, Roshani L, Chen L, Schaffer BS, Helou K, Levan G, Olsson B \& Shull JD 2007 Nonrandom pattern of chromosome aberrations in $17 \beta$-estradiol-induced rat mammary tumors: indications of distinct pathways for tumor development. Genes, Chromosomes \& Cancer 46 459-469. (doi:10.1002/gcc.20428)

Bonilla C, Boxill LA, Donald SA, Williams T, Sylvester N, Parra EJ, Dios S, Norton HL, Shriver MD \& Kittles RA 2005 The 8818G allele of the agouti signaling protein (ASIP) gene is ancestral and is associated with darker skin color in African Americans. Human Genetics 116 402-406. (doi:10.1007/s00439-004-1251-2)

Clevenger CV, Furth PA, Hankinson SE \& Schuler LA 2003 The role of prolactin in mammary carcinoma. Endocrine Reviews 24 1-27. (doi:10.1210/er.2001-0036)

Colao A \& Savastano S 2011 Medical treatment of prolactinomas. Nature Reviews. Endocrinology 7 267-278. (doi:10.1038/nrendo.2011.37)

Colletti JA II, Leland-Wavrin KM, Kurz SG, Hickman MP, Seiler NL, Samanas NB, Eckert QA, Dennison KL, Ding L, Schaffer BS et al. 2014 Validation of six genetic determinants of susceptibility to estrogeninduced mammary cancer in the rat and assessment of their relevance to breast cancer risk in humans. G3 4 1385-1394. (doi:10.1534/g3.114. 011163)

Drinkwater NR 2013 MSTAT Version 5.5.7 http://www.mcardle.wisc.edu/ mstat/index.html.

Flicek P, Amode MR, Barrell D, Beal K, Billis K, Brent S, Carvalho-Silva D, Clapham P, Coates G, Fitzgerald S et al. 2014 Ensembl 2014. Nucleic Acids Research 42 D749-D755. (doi:10.1093/nar/gkt1196)

Gould KA, Tochacek M, Schaffer BS, Reindl TM, Murrin CR, Lachel CM, VanderWoude EA, Pennington KL, Flood LA, Bynote KK et al. 2004 Genetic determination of susceptibility to estrogen-induced mammary cancer in the ACI rat: mapping of Emca1 and Emca2 to chromosomes 5 and 18. Genetics 168 2113-2125. (doi:10.1534/genetics.104.033878)

Harvell DM, Strecker TE, Tochacek M, Xie B, Pennington KL, McComb RD, Roy SK \& Shull JD 2000 Rat strain-specific actions of $17 \beta$-estradiol in the mammary gland: correlation between estrogen-induced lobuloalveolar hyperplasia and susceptibility to estrogen-induced mammary cancers. PNAS 97 2779-2784. (doi:10.1073/pnas.050569097)

Kanetsky PA, Swoyer J, Panossian S, Holmes R, Guerry D \& Rebbeck TR 2002 A polymorphism in the agouti signaling protein gene is associated with human pigmentation. American Journal of Human Genetics 70 770-775. (doi:10.1086/339076)

Kurz SG, Hansen KK, McLaughlin MT, Shivaswamy V, Schaffer BS, Gould KA, McComb RD, Meza JL \& Shull JD 2008 Tissue-specific actions of the Ept1, Ept2, Ept6, and Ept9 genetic determinants of responsiveness to estrogens in the female rat. Endocrinology 149 3850-3859. (doi:10.1210/ en.2008-0173)

Kurz SG, Dennison KL, Samanas NB, Hickman MP, Eckert QA, Walker TL, Cupp AS \& Shull JD 2014 Ept7 influences estrogen action in the pituitary gland and body weight of rats. Mammalian Genome $\mathbf{2 5}$ 244-252. (doi:10.1007/s00335-014-9504-4)

Laulederkind SJ, Hayman GT, Wang SJ, Smith JR, Lowry TF, Nigam R, Petri V, de Pons J, Dwinell MR, Shimoyama M et al. 2013 The Rat Genome Database 2013 - data, tools and users. Briefings in Bioinformatics 14 520-526. (doi:10.1093/bib/bbt007)

Li SA, Weroha SJ, Tawfik O \& Li JJ 2002 Prevention of solely estrogeninduced mammary tumors in female aci rats by tamoxifen: evidence for estrogen receptor mediation. Journal of Endocrinology 175 297-305. (doi:10.1677/joe.0.1750297)

Molitch ME 2002 Medical management of prolactin-secreting pituitary adenomas. Pituitary 5 55-65. (doi:10.1023/A:1022375429083)

Nigam R, Laulederkind SJ, Hayman GT, Smith JR, Wang SJ, Lowry TF, Petri V, De Pons J, Tutaj M, Liu W et al. 2013 Rat Genome Database: a unique resource for rat, human, and mouse quantitative trait locus data.
Physiological Genomics 45 809-816. (doi:10.1152/physiolgenomics. 00065.2013)

Ravoori S, Vadhanam MV, Sahoo S, Srinivasan C \& Gupta RC 2007 Mammary tumor induction in ACI rats exposed to low levels of 17 $\beta$-estradiol. International Journal of Oncology 31 113-120. (doi:10.3892/ijo.31.1.113)

R Core Team 2013 R: A Language and Environment for Statistical Computing. Rose-Hellekant TA, Arendt LM, Schroeder MD, Gilchrist K, Sandgren EP \& Schuler LA 2003 Prolactin induces ER $\alpha$-positive and ER $\alpha$-negative mammary cancer in transgenic mice. Oncogene 22 4664-4674. (doi:10.1038/sj.onc.1206619)

Ruhlen RL, Willbrand DM, Besch-Williford CL, Ma L, Shull JD \& Sauter ER 2009 Tamoxifen induces regression of estradiol-induced mammary cancer in the ACI.COP-Ept2 rat model. Breast Cancer Research and Treatment 117 517-524. (doi:10.1007/s10549-008-0169-0)

Sam S \& Molitch ME 2005 The pituitary mass: diagnosis and management. Reviews in Endocrine \& Metabolic Disorders 6 55-62. (doi:10.1007/s11154005-5225-z)

Schaffer BS, Lachel CM, Pennington KL, Murrin CR, Strecker TE, Tochacek M, Gould KA, Meza JL, McComb RD \& Shull JD 2006 Genetic bases of estrogen-induced tumorigenesis in the rat: mapping of loci controlling susceptibility to mammary cancer in a Brown Norway $\times \mathrm{ACI}$ intercross. Cancer Research 66 7793-7800. (doi:10.1158/0008-5472. CAN-06-0143)

Schaffer BS, Leland-Wavrin KM, Kurz SG, Colletti JA, Seiler NL, Warren CL \& Shull JD 2013 Mapping of three genetic determinants of susceptibility to estrogen-induced mammary cancer within the Emca8 locus on rat chromosome 5. Cancer Prevention Research 659-69. (doi:10.1158/ 1940-6207.CAPR-12-0346-T)

Shull JD 2007 The rat oncogenome: comparative genetics and genomics of rat models of mammary carcinogenesis. Breast Disease 28 69-86.

Shull JD, Spady TJ, Snyder MC, Johansson SL \& Pennington KL 1997 Ovary-intact, but not ovariectomized female ACI rats treated with $17 \beta$-estradiol rapidly develop mammary carcinoma. Carcinogenesis 18 1595-1601. (doi:10.1093/carcin/18.8.1595)

Shull JD, Pennington KL, Reindl TM, Snyder MC, Strecker TE, Spady TJ, Tochacek M \& McComb RD 2001 Susceptibility to estrogeninduced mammary cancer segregates as an incompletely dominant phenotype in reciprocal crosses between the ACI and Copenhagen rat strains. Endocrinology 142 5124-5130. (doi:10.1210/endo.142.12. 8530)

Shull JD, Lachel CM, Murrin CR, Pennington KL, Schaffer BS, Strecker TE \& Gould KA 2007 Genetic control of estrogen action in the rat: mapping of QTLs that impact pituitary lactotroph hyperplasia in a BN $\times$ ACI intercross. Mammalian Genome 18 657-669. (doi:10.1007/s00335-0079052-2)

Siddiq A, Couch FJ, Chen GK, Lindstrom S, Eccles D, Millikan RC, Michailidou K, Stram DO, Beckmann L, Rhie SK et al. 2012 A metaanalysis of genome-wide association studies of breast cancer identifies two novel susceptibility loci at 6q14 and 20q11. Human Molecular Genetics 21 5373-5384. (doi:10.1093/hmg/dds381)

Singh B, Bhat NK \& Bhat HK 2011 Partial inhibition of estrogen-induced mammary carcinogenesis in rats by tamoxifen: balance between oxidant stress and estrogen responsiveness. PLOS ONE 6 e25125. (doi:10.1371/journal.pone.0025125)

Spady TJ, Harvell DM, Snyder MC, Pennington KL, McComb RD \& Shull JD 1998 Estrogen-induced tumorigenesis in the Copenhagen rat: disparate susceptibilities to development of prolactin-producing pituitary tumors and mammary carcinomas. Cancer Letters 124 95-103. (doi:10.1016/S0304-3835(97)00455-2)

Spady TJ, McComb RD \& Shull JD 1999a Estrogen action in the regulation of cell proliferation, cell survival, and tumorigenesis in the rat anterior pituitary gland. Endocrine 11 217-233. (doi:10.1385/ ENDO:11:3:217)

Spady TJ, Pennington KL, McComb RD, Birt DF \& Shull JD 1999 $b$ Estrogeninduced pituitary tumor development in the ACI rat not inhibited by

Published by Bioscientifica Ltd. 
dietary energy restriction. Molecular Carcinogenesis 26 239-253. (doi:10.1002/(SICI)1098-2744(199912)26:4<239::AID-MC3>3.0. $\mathrm{CO} ; 2-\mathrm{H})$

Spady TJ, Pennington KL, McComb RD \& Shull JD 1999c Genetic bases of estrogen-induced pituitary growth in an intercross between the $\mathrm{ACI}$ and Copenhagen rat strains: dominant mendelian inheritance of the ACI phenotype. Endocrinology 140 2828-2835. (doi:10.1210/ endo.140.6.6757)

Stone JP, Holtzman S \& Shellabarger CJ 1979 Neoplastic responses and correlated plasma prolactin levels in diethylstilbestrol-treated ACI and Sprague-Dawley rats. Cancer Research 39 773-778.

Strecker TE, Spady TJ, Schaffer BS, Gould KA, Kaufman AE, Shen F, McLaughlin MT, Pennington KL, Meza JL \& Shull JD 2005 Genetic bases of estrogen-induced pituitary tumorigenesis: identification of genetic loci determining estrogen-induced pituitary growth in reciprocal crosses between the ACI and Copenhagen rat strains. Genetics 169 2189-2197. (doi:10.1534/genetics.104.039370)

Suzuki H 2013 Evolutionary and phylogeographic views on Mc1r and Asip variation in mammals. Genes \& Genetic Systems 88 155-164. (doi:10.1266/ggs.88.155)

Tachibana M, Lu L, Hiai H, Tamura A, Matsushima Y \& Shisa H 2006 Quantitative trait loci determining weight reduction of testes and pituitary by diethylstilbesterol in LEXF and FXLE recombinant inbred strain rats. Experimental Animals 55 91-95. (doi:10.1538/ expanim.55.91)

Wendell DL \& Gorski J 1997 Quantitative trait loci for estrogen-dependent pituitary tumor growth in the rat. Mammalian Genome 8 823-829. (doi:10.1007/s003359900586)

Wendell DL, Herman A \& Gorski J 1996 Genetic separation of tumor growth and hemorrhagic phenotypes in an estrogen-induced tumor. PNAS 93 8112-8116. (doi:10.1073/pnas.93.15.8112)

Wendell DL, Daun SB, Stratton MB \& Gorski J 2000 Different functions of QTL for estrogen-dependent tumor growth of the rat pituitary. Mammalian Genome 11 855-861. (doi:10.1007/s003350010168)

Wiklund J, Wertz N \& Gorski J 1981a A comparison of estrogen effects on uterine and pituitary growth and prolactin synthesis in F344 and Holtzman rats. Endocrinology 109 1700-1707. (doi:10.1210/ endo-109-5-1700)

Wiklund J, Rutledge J \& Gorski J 1981b A genetic model for the inheritance of pituitary tumor susceptibility in F344 rats. Endocrinology 109 1708-1714. (doi:10.1210/endo-109-5-1708)

Yager JD \& Davidson NE 2006 Estrogen carcinogenesis in breast cancer. New England Journal of Medicine $\mathbf{3 5 4}$ 270-282. (doi:10.1056/ NEJMra050776)

Received in final form 10 February 2015

Accepted 13 February 2015
(C) 2015 Society for Endocrinology Printed in Great Britain
Published by Bioscientifica Ltd. 